\section{RIMCIS}

\section{Hipatia Press}

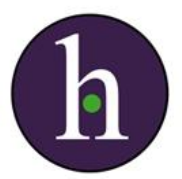

Instructions for authors, subscriptions and further details:

\title{
La Producción Socio-Institucional de Sufrimiento Social
}

Begoña Abad Miguélez ${ }^{1}$

1) Universidad del País Vasco, Spain

Date of publication: March $30^{\text {th }}, 2016$

Edition period: March 2016 - July 2016

To cite this article: Abad Miguélez, B. (2016). La Producción SocioInstitucional de Sufrimiento Social. International and Multidisciplinary Journal of Social Sciences, 5(1), 1-25. doi: 10.17583/rimcis.2016.1802

To link this article: http://doi.org/10.17583/rimcis.2016.1802

\section{PLEASE SCROLL DOWN FOR ARTICLE}

The terms and conditions of use are related to the Open Journal System and to Creative Commons Attribution License (CC-BY). 


\section{The Socio-Institutional Production of Social Suffering}

Begoña Abad Miguélez

Universidad del País Vasco

\section{Abstract}

Sociology classics -for example Marx and his concept of alienation, Durkheim and the anomie, and Weber and the disenchantment of the world- were all aware of the potential of suffering as a factor of social analysis. However, that interest in the existential meaning of suffering and its ethical and socio-political implications in social life declined almost to the point of extinction during the "glorious" years of functionalist modernity, worried addressing human relations through the pure rationality of a quantifiable abstraction capable of exorcizing the existential dimension of social relations, the true curse of the sociologist. The purpose of this paper is to reflect about suffering as a conceptual framework for the understanding of a wide range of today's social problems. In order to achieve it, we start from a basic theoretical proposition: that suffering is not just a category that, transcending the sphere of the psychological individual, allows to observe from the same perspective human problems which, albeit its differences, have a common origin in the damage inflicted by social forces on the human experience, but also a structuring element of today's sociodicea, its forms of social and institutional subjectivisation and intervention.

Keywords: social suffering, social problems, subjectivisation, social intervention, institutional intervention 


\section{La Producción Socio- Institucional de Sufrimiento Social}

Begoña Abad Miguélez

Universidad del País Vasco

\section{Resumen}

Los clásicos de la sociología - pensemos en Marx y su concepto de alienación, en Durkheim y la anomía o en Weber y el desencantamiento del mundo- fueron conscientes del potencial que se podía esperar del sufrimiento como analizador social. Sin embargo, el interés por el significado existencial y las implicaciones éticas y sociopolíticas del sufrimiento en la vida social decayó hasta desaparecer durante los años "gloriosos" de la modernidad funcionalista ocupada en tratar las relaciones humanas desde la pura racionalidad de una abstracción cuantificable capaz de exorcizar la dimensión existencial de las relaciones sociales, la auténtica maldición del sociólogo. El propósito de este artículo es reflexionar sobre el sufrimiento como marco conceptual para la comprensión de una amplia gama de problemas sociales actuales. Partimos, para ello, de una proposición teórica básica: que el sufrimiento no es sólo una categoría que permite, trascendiendo la esfera de lo individual psicológico, observar bajo un mismo prisma problemas humanos que, aunque diversos, tienen un origen común en el daño que las fuerzas sociales infringen en la experiencia humana, sino también un elemento estructurante de la sociodicea actual, de sus formas de subjetivación e intervención social e institucional.

Palabras clave: sufrimiento social, problemas sociales, subjetivación, intervención social, intervención institucional 


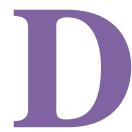

esde finales del siglo XVIII, las sociedades occidentales han experimentado un proceso de desarrollo que se evidencia en la mejora de las condiciones de vida de sus poblaciones, desde las condiciones habitacionales hasta los ingresos, pasando por los niveles de seguridad, salud y educación. Es fácil leer este proceso como reflejo de una filosofía social y política que tiene como propósito la búsqueda de la felicidad y el bienestar. Podemos encontrar explicitada esta filosofía en autores como Jeremy Bentham o John Stuart Mill. Ambos argumentaron que el propósito de las acciones humanas, incluidas las sociales y políticas, debía ser procurar el mayor grado de felicidad y bienestar al mayor número posible de personas, lo cual explicaría que el objetivo del Estado moderno fuera sostener y promover la vida digna de sus ciudadanos y ciudadanas (Sumner, 1999).

La cara oculta de esta declaración de intenciones es que la búsqueda social y política de la felicidad y el bienestar, en tanto que ideal de organización social y política, se ha distribuido de forma desigual de modo que, en la práctica, el bienestar de algunos se ha logrado a expensas del malestar y la fragilización de otros (Rummel, 1994).

¿Cómo dar cuenta, desde la sociología, de este régimen de desigualdad e injusticia social que ya no se limita a los contornos del Estado-nación sino que adquiere escala global y no responde a situaciones sociohistóricas coyunturales sino que forma parte del desarrollo de la propia modernidad? El propósito de este artículo es revisar algunos de los conceptos que se han venido utilizando en el ámbito de la sociología como anclajes teóricos y analíticos para el análisis de esta realidad social. Entablando un pequeño diálogo con dichos conceptos, con sus fortalezas y debilidades, se propone el concepto de sufrimiento social como analizador social susceptible de ser aplicado a contextos sociopolíticos y marcos institucionales concretos en los que el sufrimiento se produce y reproduce.

El punto de arranque para este diálogo es el concepto de exclusión. Durante más de veinte años ha sido el concepto utilizado para dar cuenta de las desigualdades e injusticias sociales. El término exclusión, venido a sustituir al de pobreza, implica "una nueva topografía simbólica de la sociedad" (Fassin, 1999, p. 31). Hemos pasado de una sociedad organizada verticalmente, basada en una jerarquíaque daba lugar a desigualdades, a una 


\section{Abad Miguélez - La Producción Social del Sufrimiento}

sociedad estructurada horizontalmente,con un interior compuesto por los integrados y un exterior que reúne alos excluidos.Esta nueva topografía simbólica nos remite a una consideración de las desigualdades sociales que se extiende más allá del acceso a los recursos materiales dando paso a la complejidad y multidimensionalidad de la expresión de las desigualdades sociales contemporáneas.

La multidimensionalidad y complejidad de la fragmentación social significa que existen diversos planos de desigualdad -cada uno con su especificidad pero también con vínculos de interdependencia entre los distintos campos de la sociedad- que confluyen en la generación de circuitos convergentes y progresivos de generación de exclusión social. De este modo, mientras las viejas desigualdades económicas persisten otras nuevas emergen atravesandodiversos planos del campo de la sociedad: en el territorio, el clivaje tradicional urbano/rural se sustituye por las nuevas formas de segregación urbana en las metrópolis y los procesos de hiperurbanización excluyente típicos de las ciudades globales; la instalación de una ampliada agenda de desigualdades de género que involucra desde las diversas maneras de reproducción de la tradicional dominación masculina, hasta las nuevas formas de diversidad sexual; en sociedades que expanden los tiempos biológicos de vida, la cuestión generacional se vive como otra forma de desigualdad social; la reinstalación de las desigualdades socioculturales, de origen étnico-racial, etc.

Parece lógico pensar que el análisis de las desigualdades sociales basado en la línea de ingresos (pobreza) o en la posición en la estructura productiva no puede dar cuenta de esta creciente complejidad. De este modo, la exclusión implica a sectores cada vez más amplios del cuerpo social que se ven afectados, más allá del ámbito estrictamente laboral o económico, en el ámbito formativo, socio-sanitario, residencial, etc. (Paugam, 2007).

Junto a la ampliación del campo semántico del concepto, su consideración en términos de proceso que atraviesa zonas y fases en el continuum inclusión-exclusión (Castel, 1999), visibiliza también la aportación del término en relación a su predecesor, la pobreza. En este sentido, Soulet (2005a) señala que la noción de exclusión abrió vías de análisis sociológico proponiendo sustituir la comprensión de las determinaciones de un estado (la condición de pobre) por la comprensión de 
un proceso (la exclusión) en el que confluyen un conjunto de factores económicos, sociales y simbólicos. Y al hacerlo así, no sólo facilitó la aprensión de situaciones de no-integración, sino que reavivó cuestiones centrales para el análisis sociológico relacionadas con la idea de solidaridad, de socialización, de ciudadanía, de formación de identidades individuales y sociales. Dicho de otro modo, el valor heurístico del concepto, en esta definición ampliada, se manifiesta en la posibilidad que ofrece para entender mecanismos globales de la vida en común y, más concretamente, los estados de bienestar y malestar asociados a aquellos.

Quizá esto explique que algunos autores (Duschatzky y Corea, 2002) prefieran hablar de expulsión social y no de exclusión. La idea de expulsión social refiere a la relación entre el estado de exclusión y lo que lo hizo posible. Mientras el excluido es un producto, un dato, un resultado de la imposibilidad de integración, el expulsado es resultado de una operación social, la producción social de un sujeto.

Hasta aquí, la idea de expulsión no añadiría nada nuevo a la concepción ampliada del concepto de exclusión. Ahora bien, en tanto en cuanto la idea de expulsión remite a la desaparición de los escenarios públicos y de intercambio en los que se producen las inscripciones múltiples de un sujeto, podemos entender que el expulsado no es sólo un sujeto herido físicamente (precariedad o privación material), sino también un sujeto herido moralo psicológicamente a través del menosprecio que acompaña a la falta de reconocimiento social o a la experiencia de un reconocimiento degradante (Honneth, 2010).

Ninguno de los conceptos reseñados insisten suficientemente en esta doble dimensión de la herida producida o asociada a la exclusión y/o expulsión. La pretensión de cubrir esta laguna explicaría la preferencia por el concepto de vulnerabilidad que se ha venido observando en el campo académico en los últimos años.

\section{La Vulnerabilidad Social como Condición Estructural}

Etimológicamente, vulnerable es aquella persona que puede ser herida o dañada tanto física como moralmente. Desde esta perspectiva, la vulnerabilidad se presenta como una noción potencialque obliga a interrogar 


\section{Abad Miguélez - La Producción Social del Sufrimiento}

tanto las condiciones de posibilidad de esta potencialidad (el riesgo de ser herido) como las condiciones de realización de ésta (el hecho de ser efectivamente herido) (Soulet, 2005a, p. 24).

Así definida, en principio, la vulnerabilidad remite a una potencialidad de amenaza vinculada a la condición ontológica del ser humano entendido como ser dependiente y condicionado por un mundo exterior (Butler, 2009, p. 34).

Sin embargo, en la medida en que todo ser humano es ontológicamente vulnerable, esta dimensión de la vulnerabilidad tiene un valor discriminante escaso para una aproximación sociológica a situaciones sociohistóricas y vitales concretas. El valor analítico del término surge cuando nos centramos en su dimensión estructural, esto es, en las condiciones de posibilidad y de realización efectiva de esta potencialidad en el contexto de lógicas sociales, políticas y culturales concretas las cuales, a partir de formas específicas de dominación y jerarquización, convierten en desigualdad social y política un principio ontológico común (Butler, 2009).

En el actual contexto de crisis, pero sobre todo en el marco de las políticas neoliberales vigentes, la gestión de la vulnerabilidad ontológica adquiere un matiz propio que podemos denominar "política de precarización"1. Esta nueva forma de regulación social (relaciones de poder/dominación) incluye, al menos, dos dimensiones: por un lado, una forma de gubernamentalización (gestión política de la precariedad o precarity) basada en políticas y medidas destinadas a consolidar la incertidumbre como condición/experiencia normalizada y, por otro, un modo de control y regulación basado en la interiorización de la incertidumbre como principio de definición subjetiva, como principio de subjetivación.

El resultado es la emergencia de una nueva gramática social configurada en torno a la vulnerabilidad como rasgo estructural. La crisis de la sociedad salarial y del trabajo (Castel, 1999) junto con la desinstitucionalización de la sociedad (Dubet, 2006) y la emergencia de procesos de individualización en la gestión del riesgo (Beck, 1998; Douglas, 1985; Giddens, 1990; Luhmann, 1993) son los rasgos que estructuran las narrativas sobre la nueva gramática social. Excede los límites de este trabajo describir con detalle cada uno de ellos. No obstante, sí me interesa detenerme en dos ejes que sustentan la nueva gramática tal y como se desarrolla en el marco de las políticas 
neoliberales de la modernidad avanzada, y que resultan claves para entender la centralidad del término vulnerabilidad en su dimensión estructural.

El primero alude a un proceso de privatización de los derechos, es decir, al proceso en virtud del cual el traspaso del poder de determinar su contenido acaba recayendo en manos privadas de modo tal que lo que, en el contexto del Estado de Bienestar y la bonanza económica, era exigible al Estado (derecho a la salud, a la educación, a la jubilación...) pasa a ser considerado un producto que sólo podrá ser adquirido por quienes tengan capital para ello. El segundo es la consecuencia esperada de una desocialización y despolitización creciente de la problemática social, o mejor aún, de la interpretación de la cuestión social, todo ello en aras de un potente proceso de individualización que conduce a la búsqueda de soluciones biográficas para problemas sistémicos (Sennett, 2001; Beck, 1998).

La individualización en la gestión del riesgo (incertidumbre, precariedad) implica modalidades y referentes deconstrucción de individualidad que ensalzan, reforzados por discursos institucionales, el esfuerzo y las capacidades individuales en la resolución de los problemas cotidianos. Nos encontramos, pues, ante un traspaso de la responsabilidad de la gestión de las condiciones de precariedad a los propios individuos quienes, de este modo, asumen dichas condiciones como parte de la experiencia. Este discurso pretende generar individuos autónomos, capaces de elaborar su propio proyecto personal y de responsabilizarse del devenir de dicho proyecto, esto es, sujetos emprendedores de sí mismos que asumen éxitos y fracasos en términos individuales y psicológicos pues el fracaso en la gestión del proyecto se interioriza como auto culpabilización (Genard, 2009). Sobre este sentimiento de responsabilidad y culpa acaba, en última instancia, sustentándose la definición social como "sujetos carentes", "sujetos por defecto" a los que de alguna manera hay que tutelar mediante prácticas filantrópicas, caritativas, paternalistas, alejadas del principio de justicia y cargadas de un alto componente de control y vigilancia ${ }^{2}$.

Desde la antropología se ha desarrollado un análisis en términos similares. Jean-Louis Genard (2009) vincula la experiencia de vulnerabilidad a un cambio de coordenadas en la interpretación antropológica de la acción y del individuo. Su planteamiento es que en la modernidad se produce la emergencia de una interpretación responsabilizante de la acción que, tras 
imponerse a formas previas de interpretación como el destino de la tragedia griega o la deshonra de las sociedades arcaicas, coloca al individuo en el centro de la tensión kantiana entre libertad-determinismo o responsabilidadirresponsabilidad. Esta tensión se ha resuelto mediante dos estrategias distintas en dos fases de desarrollo que él identifica como primera modernidad (de la Edad Media hasta el siglo XVIII) y segunda modernidad (del siglo XVIII en adelante).

La primera estrategia o coordenada antropológica, que él denomina disyuntiva, predomina durante la primera modernidad. Basada en dispositivos sociales como el consentimiento, el contrato o el juramento, piensa la acción en términos de responsabilidad e intencionalidad, es decir, del lado de la libertad/autonomía y frente a cualquier expresión de determinismo, ya sea el determinismo astral, la fortuna, la gracia, el pecado original o la providencia. Esto da lugar a una interpretación de opuestos: los individuos pueden ser o lo Uno o lo Otro, es decir, responsables, capaces, normales, o irresponsables, incapaces, anormales, locos.

La segunda estrategia, que él denomina conjuntiva, comienza a emerger en la segunda modernidad de la mano de las ciencias de lo humano (medicina, psicología, psicoanálisis, biología, sociología, genética) que abren la puerta a la dimensión de la irresponsabilidad-determinismo al explicar parte de la acción a partir de referencias como el carácter, los humores, el inconsciente, el determinismo genético, los posicionamientos sociales y/o el habitus. A partir de aquí el ser humano puede ser al mismo tiempo lo Uno y lo Otro, situado en una posición precaria e incierta entre la responsabilidad y la irresponsabilidad, entre la libertad y el determinismo. En este nuevo escenario el individuo se revela tanto en sus emociones y padecimientos como en sus manifestaciones cognitivas y racionales. Los dos elementos conforman un todo del que, en última instancia, es responsable el propio individuo. Porque lejos de devolver una imagen de pasividad volcada en el sometimiento a la irracionalidad de las emociones, la interpretación responsabilizante de la acción que define las coordenadas antropológicas de la segunda modernidad conlleva la puesta en acción de las propias capacidades para gestionar la antinomia responsabilidad-irresponsabilidad. La fragilidad, vulnerabilidad del individuo se entiende aquí asociada a la responsabilidad de la gestión del propio yo. 
La oscilación entre los dos términos de la antinomia da como resultado la coexistencia de discursos opuestos. Para ilustrar este extremo Genard (2009, p. 38) pone como ejemplo la consideración de la palabra víctima: junto a la reivindicación de la preocupación por las víctimas, se desarrollan también críticas al "proceso de victimización" utilizado como estrategia para la obtención de determinadas ventajas sociales. La convivencia de opuestos es perceptible también en las políticas y prácticas en el campo de laintervención social al oscilar entre la protección o asistencia y la responsabilización (Genard, 2009, p. 42-43).

En cualquier caso, la realización de la vulnerabilidad estructural, es decir, su materialización en situaciones concretas, se tematiza bajo la forma de una doble herida: una herida física que podemos asociar, para el tema que nos ocupa, con las políticas de precarización (i.e. privatización de derechos, retirada de los medios sociales de contención y/o protección); y una herida psíquica que afecta a la subjetividad (i.e. despolitización y desocialización, individualización y psicologización de los problemas sociales) ${ }^{3}$. Así, el sufrimiento (la herida) vertebra el ser psíquico por el ser social (Soulet, 2005a, p. 29), lo que convierte al sufrimiento en un analizador potente que permite comprender la vulnerabilidad en sus materializaciones existenciales, objetivas y subjetivas, concretas.

\section{Sufrimiento como Analizador Social}

El sufrimiento humano ha sido el inspirador de la mayoría de los trabajos de sociología. De hecho, todos los problemas sociales, desde la exclusión de oportunidades de vida hasta la injusticia y la violencia, tienen detrás alguna forma de sufrimiento social. Los clásicos de la sociología -pensemos en Marx y su concepto de alienación, en Durkheim y la anomía o en Weber y el desencantamiento del mundo- fueron conscientes del potencial que se podía esperar del sufrimiento como analizador social,por más que no usaran expresamente este término y su interés estuviera focalizado hacia los poderes sistémicos y estructurales configuradores de un proceso de cambio social, más que hacia las experiencias o significados existenciales de dicho procesoen sus realizaciones institucionales concretas. 
No obstante, esta creencia en el potencial analizador del sufrimiento social decae hasta casi desaparecer durante los años "gloriosos" de la interpretaciónfuncionalista ${ }^{4}$. Gouldner (1968) mantiene que, al alejarse del lenguaje del sufrimiento, esta sociología debe afrontar una doble acusación: indiferencia hacia la humanidad e ignorancia de la experiencia social de la modernidad. Esta doble acusación supone que el aparente desinterés de la sociología por el significado existencial y las implicaciones éticas y sociopolíticas del sufrimiento en la vida social puede ser el reflejo de la tensión entre las expectativas sobre el progreso moral y la escalada de violencia simbólica y estructural que sacude la historia reciente de la modernidad; tensión que tradicionalmente se ha venido resolviendo ocultando la cara más oscura y cruel de un ordenamiento social que se presenta a sí mismo como paladín de la razón y el progresobajo un manto estadístico que implica tratar las relaciones humanas desde la pura racionalidad de una abstracción cuantificable.

En una línea similar de rechazo hacia el sufrimiento como analizador podemos situar los planteamientos que lo consideran, tanto en su dimensión física (cualquier aflicción o daño producido, vivido físicamente) como psíquica (cualquier aflicción percibida en la identidad cognitiva o afectiva) como una experiencia netamente individual e individualizante, difícilmente traducible a palabras y compartible por alguien que no haya experimentado algo parecido de modo que abordar su estudio implicaadentrarnos en terrenos que podemos considerar psicológicos. Frente a esta posición siempre podemos argumentar que los fenómenos sociales nunca son sólo sociales. Por definición son complejos y multidimensionales de modo que, si bien la primera explicación debe partir de otros hechos sociales, la comprensión holística de los mismos sólo se logra mediante la explicitación de otros elementos -fundamentalmente psicológicos- porque la mayoría de los hechos sociales son en realidad hechos psicosociales (De Gaulejac, 2009, p. 25). Partiendo de aquí la recomendación epistemológica es clara: tomar en cuenta la dimensión existencial de las relaciones sociales de modo que "la «vivencia» deja de ser considerada como la maldición del sociólogo, como una dimensión turbia, y se convierte en una dimensión irreductible de lo que hace a la sociedad" (ibídem, 2009, p. 26). 
Pero si los fenómenos sociales no son únicamente sociales, los fenómenos psicológicos tampoco son exclusivamente psicológicos. Si bien el sufrimiento es una experiencia individual, al mismo tiempo esta experiencia ha de entenderse desde una perspectiva colectiva. Cada persona experimenta individualmente el dolor, pero lo hace en el contexto de unos parámetros culturales. El grupo social normaliza, mediante su creación cultural, la experiencia del sufrimiento (pensemos, por ejemplo, en los ritos de paso o iniciación) produciendo así su justificación (cada época histórica ha aceptado o rechazado determinados sufrimientos) y su naturalización (los miembros de un grupo social tienden a ver como naturales determinadas experiencias del dolor, su sentido o sentidos, las formas de padecerlo y los mecanismos para afrontarlo) (Madrid, 2010). Todos estos condicionantes del sufrimiento han formado parte, históricamente, de las raíces culturales comunitarias de cada sujeto.

La virtual potencialidad del concepto de sufrimiento para comprender las conexiones entre lo social y lo existencial puede explicar el reciente interés que ha suscitado este campo de estudio; interés observable en disciplinas tan dispares como la filosofía política (Renault, 2009), la sociología y la antropología (Wilson y Brown, 2011) e incluso la criminología y el derecho (Hillyard et al., 2004).

En todos los casos el concepto puesto en juego es el de sufrimiento social. Siguiendo a Wilkinson (2005) podemos señalar que el sufrimiento social es una categoría analítica que permite englobar bajo una misma etiqueta problemas humanos que, aunque diversos, tienen orígenes y consecuencias similares: los daños que la fuerza social infringe en la experiencia humana. En este sentido, deriva de lo que el poder institucional, económico y político hace en y a la gente, así como de las formas en que ese poder define las respuestas socialmente válidas disponibles para afrontar ese sufrimiento. Así definido permite, por un lado, derribar barreras categoriales que separan en ámbitos diversos las distintas formas de sufrimiento y, por otro, entender que sea cual sea la forma que adopte, el sufrimiento trasciende la esfera de los individual/psicológico hacia la consideración del sufrimiento como experiencia social resultante de un proceso también social. Este es el argumento que, desde la filosofía política, desarrolla Renault (2009) cuando afirma que 
the notion of social suffering aims to describe these connections between subjective and social aspects of experiences of injustice and domination (especially of injustice as poverty and domination as violence). [...] This notion points out that experiences of what is unbearable have the power to transform social relation (by attempts made to transform them or to escape) as well as individual subjectivity: one has to mobilize psychic defenses to adapt to what is unbearable, and these defenses produce new effects on social relations (for instance, not only a greater social isolation and vulnerability to violence but also a tendency to use violence as a means of selfexpression). On the other hand, the notion of social suffering stresses that in these experiences, the origin of suffering is social and not merely biographical, in the sense that it can be traced back to general social relations as well, and not only to contingent biographical events and structures of family life (Renault, 2009, p.160) ${ }^{5}$

El término, como tal, comienza a ser utilizado en el campo de la antropología en el contexto de estudios sobre el dolor y el sufrimiento desarrollados desde una perspectiva etnográfica (Morris, 2002; Wilkinson, 2005; Kleinman y Van der Geest, 2009). En estos trabajos se profundiza en la validez analítica del concepto en un doble sentido pues permite vincular problemas sociales y de salud de toda índole y, al mismo tiempo, permite reinterpretar moralmente las bases de la sociedad moderna.

En el ámbito de la sociología cabe destacar las aportaciones de Bourdieu. En su libro La miseria del mundo (1999) ejemplifica bien esta perspectiva abordando distintas dimensiones del sufrimiento social en distintos ámbitos culturales y sociales. Su línea de investigación ha sido continuada por algunos de sus discípulos (Wacquant, 2000, 2007, 2010). En el ámbito de la filosofía social y la teoría crítica cabe destacar las aportaciones de Axel Honneth $(2010,2011)$ fundamentalmente por lo que se refiere a su reflexión sobre las tres esferas en las que se encarna el desprecio o sufrimiento: físico o maltrato, social o privación de derechos y exclusión, y psicológico o injuria contra la dignidad y el honor ${ }^{6}$.

Todos estos trabajos aportan una extensa evidencia sobre cómo las dimensiones sociales del sufrimiento se producen en contextos sociales, culturales e institucionales, incluso cuando sus políticas y programas han 
sido diseñados para subvertir ese sufrimiento. Sin detenernos demasiado en lo que Merton pudiera decirnos sobre las consecuencias no deseadas de la acción que se intuyen en esta última conclusión, lo interesante aquí es señalar que, con algunas excepciones, la mayoría de los trabajos publicados se centran en la documentación de los puntos de vista de quienes experimentan alguna forma de sufrimiento relatando así las condiciones de existencia que, desde la adversidad y la desigual distribución del dolor, delimitan los contornos de dicho sufrimiento (Wilkinson, 2013).

Si bien este tipo de enfoque permite sentar las bases para una política de reconocimientocentrada en la superación del desprecio (Honneth, 2010, 2011), fallan a la hora de construir un marco analítico más amplio sobre las dinámicas de poder, los procesos culturales y políticos estructuradores de esas experiencias. En la medida en que se centran en experiencias y relatos particulares, muy pocos pueden ir más allá y aventurar cómo estos relatos y experiencias pueden ser útiles para fundamentar procesos más amplios de cambio social y cultural ya que obvian la evidente dimensión política del sufrimiento social (Wilkinson, 2013, p. 124). Hay que recordar que "el sufrimiento social puede tener múltiples causas que se pueden agrupar en el tríptico represión, explotación, exclusión. Cada una de estas situaciones es dolorosa objetivamente y difícil de vivir subjetivamente" (De Gaulejac, 2009, p. 201). Aquellos obligados a ocupar un lugar social que los invalida, los descalifica, los instrumentaliza o los desconsidera, sienten la violencia de los espacios sociales e instituciones que los mediatizan. "Se trata de «víctimas estructurales», en el sentido de que el sufrimiento es provocado por las contradicciones, las incoherencias y las ambigüedades de las instituciones" (ibídem, 2009, p. 200) y de la estructura social.

Desde esta perspectiva podemos entender que el potencial del sufrimiento como analizador social no derivaría tanto, o no sólo, de la introducción del pathos en lo político social (Fassin, 1999),loque equivaldría a pensar sobre el sufrimiento, sino del abordaje de la producción del pathos en y desde lo político, lo que equivaldría a pensar con el sufrimiento. Utilizando el término foucaultiano de problematización pasaríamos de analizar los efectos a analizar las causas entendidas como prácticas de poder discursivas y no discursivas que no sólo gestionan, sino que también producen sufrimiento en contextos sociopolíticos concretos y en marcos institucionales delimitados ${ }^{\underline{7}}$. 


\section{Contextos Sociopolíticos y Marcos Institucionales: La Producción del Sufrimiento Social}

Problematizar implica atender a dos dimensiones de la realidad: las racionalidades políticas y las tecnologías de gobierno. Para nuestro caso, las racionalidades políticas se refieren al contexto sociopolítico de las políticas neoliberales de precarización. Las tecnologías de gobierno se refieren a los arreglos institucionales y legales, es decir, a las microdinámicas de poder a través de las cuales funcionan las racionalidades políticas.

Hemos mencionado más arriba hasta qué punto las políticas de precarizaciónneoliberales vigentes tienen efectos sobre la sujeción y la subjetividad los cuales pueden ser leídos en clave de sufrimiento. En esta línea, cabe señalar la proliferación en los últimos años de estudios y trabajos que, basados en los trabajos de Foucault sobre conocimiento, poder y gubernamentalidad, intentan desentrañar el nexo entre neoliberalismo, sujeción y subjetividad partiendo de la concepción antropológica subyacente o implícita en el neoliberalismo.

El neoliberalismo convierte la actividad económica en la matriz de las relaciones políticas y sociales de modo tal que el eje de rotación de la nueva gramática social no será, como en el liberalismo clásico, el intercambio sino la competición, convertida así en el rasgo diferencial del nuevo sujeto social y político: el homo-economicus. Éste, visto como entrepreneur, es un individuo activo que toma decisiones para invertir en sí mismo de cara a mejorar su situación y la de los suyos. Esto no significa solamente, como señalan Rose y Miller (1992), una recuperación de los valores liberales de auto-confianza y autonomía entendidos como condiciones necesarias para la autoestima y el progreso personal, sino que supone una verdadera apuesta por la iniciativa empresarial y la capitalización de la existencia como objetivo a desarrollar a través de actos de cálculo (coste-beneficio) y de inversión. Sobre estos principios se autogobiernan los individuos, que ya no son ciudadanos sino empresarios de sí mismos, pero también se estructuran los poderes de gobierno. El gobierno se desocializa de cara a maximizar la conducta de los individuos en todos los ámbitos de la vida social, incluidos 
aquellos que formalmente se desarrollan lejos o aparte de una lógica económica: escuelas, hospitales, servicios sociales, etc.

Pero problematizar la forma de gobierno liberal exige analizar también las tecnologíasde gobiernoa través de las cuales se ponen a funcionar las racionalidades políticas. A través de estas tecnologías de gobierno se produce lo que Rose y Miller (1992, p. 278) denominan "acción a distancia”, una acciónque permite al Estado pasar de ejercer su dominación de forma directa, a través de la represión física que produce daño físico, a una dominación más sutil e indirecta, ejercida a través de lo que Tilly (1997) denomina "codazos invisibles", que afecta a la subjetividad produciendo, en no pocas ocasiones, sufrimiento o daño psíquico ${ }^{8}$.

Las tecnologías de gobierno nos remiten a políticas de precarización ejercidas a través de la experiencia individual y subjetiva del sufrimiento. Esto tiene consecuencias en términos políticos pues si bien el daño físico puede ser observable y objetivable y, en este misma medida, imputable en última instancia como "delito de los Estados y de los mercados" (Rivera Beiras, 2014), el daño psíquico no es directamente observable ni fácilmente imputable de modo tal que el "sujeto sufriente" debe demostrar ante las instituciones su condición de vulnerable. En este contexto, mientras el sujeto se vuelve más vulnerable y dependiente, al menos sicológicamente, de los sistemas expertos, el trabajo institucional de reconocimiento se convierte en una suerte de magistratura moral que evalúa, reconoce o desestima la condición de sujeto sufriente y los derechos a los que ésta puede dar lugar.

Son múltiples las instancias en las que se materializa la acción a distancia del poder a través del ejercicio del conocimiento experto e institucional ${ }^{9}$, desde las prisiones a los centros de internamiento (de menores o de inmigrantes) pasando por instancias judiciales. Una de ellas, en la que se centra este artículo, es la del trabajo social. Tomándolo como referencia podemos ver cómo funcionan los codazos invisibles en la relación institucional y en la configuración del sujeto como sujeto sufriente dependiente de un trabajo institucional de reconocimiento.

Existe una literatura relativamente extensa sobre el trabajo social y el poder (Chambon, Irving y Epstein, 2001; ZamanilloPeral y Martín Estalayo, 2011; Salcedo Megales, 2010). Menos extensa es la referida a los dilemas o tensiones que deben resolver estos profesionales en el ejercicio de su 
profesión (Cañedo Rodríguez, 2011; Ballestero Izquierdo, Úriz Pemán y Viscarret Garro, 2012). En un trabajo anterior (Abad Miguélez y Martin Aranaga, 2015) desarrollamos un argumento en esta línea. Planteamos allí que en el contexto social y político actual, marcado por la privatización de lo social, la psicologización de la precariedad-vulnerabilidad, la despolitización y desocialización progresiva de la cuestión social, los y las trabajadoras de lo social se encuentran atrapadas en una doble vinculación. Por un lado, la vinculación profesional que les liga con la política a la que de un modo u otro representan y deben dar respuesta y que, en última instancia, exige adaptaciones múltiples como la realización de intervenciones formalistas y reglamentistas o, lo que es lo mismo, ajustarse a la norma o justesse tal y como lo define Soulet (2005b, 2014); sustituir planificaciones a medio y largo plazo por procedimientos de "ensayo y error" sometidos a técnicas racionalizadoras de la gestión; "vender" su imagen en términos de competencia y eficacia, o lo que es lo mismo, justificacion en términos de Soulet. Por otro lado, tendríamos la vinculación que les liga a los usuarios/as de los servicios expertos que estos profesionales ofrecen. Esta vinculación moviliza la concepción del trabajo en lo social como acción social emancipadora y transformadora (principio de justice según Soulet) que ha acompañado y definido buena parte del trabajo de estos profesionales desde su constitución.

La tensión entre estos principios deviene de la necesidad de trabajar con el sufrimiento de los otros, lo cual genera no pocas tensiones y sufrimientos en los propios profesionales. Resolver estas tensiones, es decir, gestionar el propio sufrimiento y posicionarse ante el de los demás, les obliga a un ejercicio de autorreflexión y autoconceptualización profesional que, en última instancia, puede dar como resultado otras tantas figuras o tipologías profesionales merecedoras de análisis para entender cómo funcionan en la práctica los sistemas expertos que el Estado utiliza para gobernar en la distancia.

Pues bien, si escuchar a quienes practican la intervención social resulta clave para entender el funcionamiento y efectos de las tecnologías de poder, no lo es menos el acercamiento a aquellos que más directamente las experimentan: los usuarios/as. En este caso, la literatura al respecto es notablemente más escasa que la referida a los y las profesionales del trabajo 
social, sobre todo la destinada a trascender experiencias y relatos individuales de sufrimiento para alcanzar alguna suerte de comprensión sobre los procesos sociales y culturales estructuradores de esas experiencias. Entre los más destacables estarían los trabajos de Didier Fassin (1999, 2003). Su tesis gira en torno a los usos políticos del cuerpo, en concreto a mostrar cómo "sumisos a relaciones de poder, los dominados llegan a utilizar su cuerpo como fuente de derechos" (Fassin, 2003, p. 54). Porque, añade, más que de la imposición de un bio-poder, las demandas a las instituciones implican la puesta en práctica de una biolegitimidad, una política "en la cual es el cuerpo el que da derecho, a título de la enfermedad (justificación de atención médica) o del sufrimiento (apelando a la compasión), ya sea a una tarjeta de residencia, ya sea a una ayuda financiera de emergencia" (ibídem, 2003, p. 52-53). Analiza cómo en las demandas y relaciones con las instituciones la necesidad de contar(se) o de mostrar(se) se hace obligación porque, precisamente por la psicologización del sufrimiento, se hace necesario hacerlo verbo, mostrarlo y demostrarlo, lo que muchas veces convierte el cuerpo en centro del proceso de incorporación de la miseria, el dolor, la necesidad y la precariedad. La implicación última de este proceso es la necesidad de justificación, de acreditación constante (Feher, 2009), de promoción institucional de la idea de mérito, de metas personales y colectivas que alcanzar, así como de la competencia, extendida al terreno de la moral (Wacquant, 2010). Porque en este proceso de justificación/acreditación los sujetos deben mostrar y demostrar que son merecedores de atención para lo cual deben desplegar, al menos retóricamente, todos los tópicos del infortunio: desde la necesidad a la compasión, pasando por el mérito (Fassin, 2003, p. 60-62; De Gaulejac, 2009, p. 171).

Que los sujetos deban exponerse ante el Estado, o ante sus representantes o expertos, para obtener alguna suerte de reconocimiento social, y que en muchas ocasiones deban hacerlo ante "una pluralidad de instituciones y agentes que tienen en diversos grados, los poderes de decisión sobre su existencia" (Fassin, 2003, p. 70), produce un efecto de doble victimización (culpabilización individual y naturalización del sufrimiento) con consecuencias esperadas sobre la producción de los sujetos, sobre su subjetivación. 
Simmel (1998) apuntaba ya esta hipótesis en su libro sobre los pobres. Recibir asistencia es la seña de identidad de la condición de pobre, de pertenencia a un estrato específico de la población que, por otro lado, se representa como desvalorizado a partir de su condición de dependiente respecto al resto de la sociedad. Porque recibir asistencia, señala Paugam (2007, p. 152), implica "recibir todo de los demás sin poder establecer una relación de complementariedad o reciprocidad al menos a corto plazo". Y esto genera efectos en la subjetividad porque "el «pobre», receptor de ayudas especialmente dirigidas a él, debe aceptar vivir, al menos temporalmente, con la imagen negativa que de él proyecta la sociedad y que termina por interiorizar; esta imagen se asocia con dejar de ser útil y formar parte de aquellos que en algunas ocasiones son considerados «indeseables»".

La interpretación de Simmel correspondería a lo que Genard (2009) denomina estrategia antropológica disyuntiva basada en la clasificación social en dos grupos: los individuos responsables, capaces, normales, y los irresponsables, incapaces, anormales o locos sobre los que habría que intervenir para su transformación. El fracaso en la intervención recaería, en última instancia, en el profesional como representante del ordenamiento social. La situación actual, de estrategia antropológica conjuntiva según Genard, implica una doble victimización y sufrimiento subjetivo en la asistencia en la medida en que se transmiten mensajes que pasan por la activación y la movilización de la iniciativa individual en el contexto de una lógica de responsabilización y culpabilización del fracaso como fracaso individual y no social. Pero, además, en la medida en que cada vez más prestaciones sociales dejan de concebirse como derechos sociales para pasar a concebirse como derechos subordinados a la implicación de la subjetividad bajo la forma de un contrato para el desarrollo de un proyecto personal concreto, el receptor pasa a concebirse como deudor con el consiguiente coste afectivo y de control (Ávila Cantos y García García, 2013, p. 17).

La segunda fuente del sufrimiento se relaciona con el aumento de la severidad de los requisitos para beneficiarse de la ayuda pública, así como el incremento de la complejidad y tardanza de los trámites burocráticoadministrativos. Este último aspecto remite a la gestión y control del tiempo, concretamente a la lógica y la experiencia de la espera (Schweizer, 2010) como nueva forma de gubernamentalidad. La gente inscrita en el reino del 
no (no casa, no trabajo, no sanidad, etc.) aprende a esperar por los mínimos estándares de vida (Cervio y D'hers, 2014, p.50). Pero esta espera permea los cuerpos generando sufrimiento en forma de sensación de impotencia "ante la necesidad (y la responsabilidad) de «activarse», «moverse», «no quedarse parado», en una suerte de movimiento autómata que debe reemplazar la pasividad y la dependencia propias de una época pasada" (Ávila Cantos y García García, 2013, p.16; De Gaulejac, 2009, p. 172).

Ahora bien, si las prácticas y el saber constituyen al yo, ¿qué lugar queda para la iniciativa personal y la subversión del sufrimiento? Si las prácticas normativas constituyen formas de subjetividad, el cambio hay que buscarlo en las tácticas y en la capacidad de resistencia de los dominados, "capacidad de resistir a la multitud de solicitaciones a las cuales están sometidos -a través del silencio, la capacidad de sacar ventaja, la contestación- verdadero aprendizaje de la socialización en la dominación" (Fassin, 2003, p. 71). La resistencia, entonces, pasaría por estrategias de desnaturalización del sufrimiento y de ruptura con un lugar victimizado a partir del desarrollo de una cierta capacidad de reflexión sobre sí mismos como sujetos de derechos, y por la resignificación de su historia vital.

\section{A Modo de Cierre}

El concepto de bienestar conjuga una dimensión subjetiva,alineada con la percepción subjetiva del bienestar personal, con una dimensión objetiva asociada a la posesión de un cierto confort material. Del mismo modo, el sufrimiento en su múltiples formas, desde la privación material a la privación social y el menosprecio, pasando por la desposesión de derechos y la exclusión social, vincula condiciones de vida precarias, difíciles e inestables con situaciones de vulnerabilidad identitaria asociadas a una imagen invalidada del propio yo (De Gaulejac, 2009, p. 199).

A lo largo del texto hemos intentando argumentar cómo el sufrimiento social definido en su doble dimensión se conforma como un elemento estructurante de la sociodiceaactual (Giner, 2014), de sus formas de subjetivación e intervención social en contextos institucionales concretos. Analizar los distintos dispositivos y prácticas de subjetivación que contribuyen a la producción de sufrimiento social en dichos contextos nos 
permite entender las dinámicas de poder que no sólo generan daño social expresado en datos agregados como paro, desahucios, pobreza, recortes en servicios sociales, etc.-, sino que modulan como sufrimiento la experiencia de los sujetos en torno a ese daño. De este modo, no sólo se logra un conocimiento exhaustivo de"los fundamentos morales del gobierno de los ilegítimos del mundo y del tipo de ciudadanía que él produce" (Fassin, 2003, p. 70), sino que podemos contribuir a la implementación de políticas y prácticas de intervención social que reduzcan la producción institucional de sufrimiento social.

\section{Notas}

${ }^{1}$ La política de precarización supone que el poder no sólo "construye" (define) ciertos grupos como precarios, sino que usa la precariedad como instrumento de poder y gobierno.

2 La dimensión de control y vigilancia nos habla de un individualismo negativo, desocializante (Castel, 1999), que constriñe los límites de la individualización a los contornos de la definición institucional. Desde el punto de vista de los sujetos nos encontramos con un efecto paradójico: el mandato de mayor autonomía y responsabilización se traduce en mayor dependencia institucional en tanto en cuanto el reconocimiento social de la precariedad pasa necesariamente por el reconocimiento institucional.

${ }^{3}$ La vulnerabilidad, en su etimología, supone la contingencia o proximidad de un daño. Para que se produzca efectivamente ese daño deben darse tres condiciones: 1) un evento potencialmente adverso, es decir, un riesgo; 2) una incapacidad de respuesta frente a tal contingencia (ya sea debido a la ausencia de defensas pertinentes o a la carencia de fuentes de apoyo); 3) falta de habilidad para adaptarse al nuevo escenario generado por la materialización del riesgo. De este modo, si la potencialidadde ser herido es común debido al carácter estructural de la vulnerabilidad (políticas de precarización), el que efectivamente la padece es debido a sus particularidades singulares (porque es menos vigilante, prudente, previsor, más débil o menos protegido). Es herido así el que no se halla en situación de hacer frente con sus propios recursos a las exigencias del nuevo escenario (Soulet, 2005a, p. 28).

${ }^{4}$ Señala Salvador Giner (2014, p. 294) que Talcott Parsons, al que podemos considerar aquí el máximo exponente del pensamiento funcionalista, "con frecuencia soslaya la responsabilidad humana y, por lo tanto, el problema sociológico del mal".

${ }^{5}$ Traducción de la autora: la noción de sufrimiento social pretende describir las conexiones entre los aspectos subjetivos y sociales de experiencias de injusticia y dominación (especialmente injusticia como pobreza y dominación como violencia). Por otro lado, este concepto destaca las dinámicas subjetivas de la experiencia social de la injusticia y la dominación, se centra en el hecho de que estas situaciones contienen algo insoportable de modo que producen tendencias prácticas de transformación, escape o adaptación si las dos primeras respuestas no son posibles. Este concepto indica que las experiencias de lo que es insoportable tienen el poder de transformar la relación social (mediante tentativas de 
transformación o escape) así como la subjetividad individual: cada uno tiene que movilizar defensas psíquicas para adaptarse a lo que es insoportable, y estas defensas producen nuevos efectos sobre las relaciones sociales (por ejemplo, no sólo una mayor aislamiento social y vulnerabilidad ante la violencia, sino también una tendencia a usar la violencia como medio de autoexpresión). Por otro lado, la noción de sufrimiento social enfatiza que en estas experiencias el origen del sufrimiento es social y no meramente biográfico en el sentido de que su origen puede encontrarse también en relaciones sociales generales y no sólo en acontecimientos biográficos contingentes y en estructuras de la historia familiar.

${ }^{6}$ La aportación de Honneth parece relevante en tanto en cuanto desarrolla la contrapartida del reconocimiento en términos de sufrimiento. No obstante, si bien su teoría posibilita una "disección" de las dimensiones o expresiones del sufrimiento, no así de los procesos por los que se encarna, produce y reproduce en contextos institucionales específicos. En este sentido, contribuye a profundizar en el pensamiento sobre el sufrimiento, pero no tanto en el pensamiento con el sufrimiento.En cualquier caso, Honneth posibilita con su obra desarrollar y consolidar una línea de pensamiento que tiene un profundo arraigo en autores de la Escuela de Frankfurt como Theodor Adorno o Walter Benjamín.

${ }^{7}$ Es este proceso de problematización el que permite poner en valor el potencial analizador del concepto propuesto en relación, o por comparación, con otros afines como el de anomia, alienación o violencia simbólica. Todos ellos tienen en común la comprensión del sufrimiento como efecto derivado del funcionamiento estructural y sistémico. El valor añadido del sufrimiento social, tal y como se plantea en este texto, es doble: por un lado, pretende añadir al análisis de los efectos el de las causas, es decir, procedimientos y practicas concretas en virtud de las cuales se genera dicho sufrimiento y, por otro lado, permite vincular las dos dimensiones básicas, social y psicológica, de la realidad social.

${ }^{8}$ Esta segunda dominación se ejerce a través de un conjunto de agentes y agencias encargadas de operacionalizar los programas de gobierno bajo el abrigo de un principio de legitimidad concreta: su constitución como sistemas expertos (Rose y Miller, 1992).

${ }^{9}$ El sufrimiento social que estamos considerando a lo largo de este texto se asocia con posiciones sociales que invalidan, descalifican, instrumentalizan o desconsiderande modo que es una noción relacional surgida de procesos intersubjetivos enmarcados en contextos institucionales y sociales concretos (De Gaulejac, 2009, p. 198).

\section{Referencias}

Abad Miguélez, B. y Martin Aranaga, I. (2015). El Trabajo Social ante la crisis. Nuevos retos para el ejercicio profesional de los y las trabajadoras sociales. Cuadernos de Trabajo Social, 28(2), 175-185. doi: 10.5209/rev_CUTS.2015.v28.n2.48765

Ávila Cantos, D. y García García, S. (2013). Lógica de escasez en los derechos y administración de la pobreza. IV Congreso de la Red Española de Política Social (REPS) Las políticas sociales entre crisis $y$ post-crisis. 6-7 junio 2013. Universidad de Alcalá, Madrid. 
Consultado

desde http://www3.uah.es/congresoreps2013/Paneles/panel7/sesion2/apropia cionindebida@g mail.com/TCLogica.pdf

Ballestero Izquierdo, A., Úriz Pemán, M. J., y Viscarret Garro, J. J. (2012).

Dilemas éticos de las trabajadoras y los trabajadores sociales en España. Papers, 97(4), 875-898.

Beck, U. (1998). La sociedad del riesgo. Hacia una nueva modernidad. Barcelona: Paidós.

Bourdieu, P. (1999). La miseria del mundo. México: Fondo de Cultura Económica.

Butler, J. (2009). Frames of War. When is Life Grievable? London: Verso.

Cañedo Rodríguez. M. (2011). ¿Y esto a quién se lo cuento, al ayuntamiento? Trabajadores sociales entre la vocación y la burocracia. Un análisis antropológico del modelo de intervención de los Servicios Sociales a partir de la etnografía de una red asistencial madrileña. Cuadernos de Trabajo Social, 24,135-153.

Castel, R. (1999). Les métamorphoses de la question sociale. Paris: Gallimmard.

Cervio, A. L., y D'hers, V. (2014). Social Time, Bodies and the "Logic of Waiting" in the Configuration of Urban Sensibilities. Current Urban Studies, 2, 49-56. doi: 10.4236/cus.2014.21005

Chambon, A. S., Irving, A., y Epstein, L. (Eds.) (2001). Foucault y el trabajo social. Granada: Editorial Maristán.

De Gaulejac, V. (2009). Las fuentes de la vergüenza. Madrid: Mármol Izquierdo.

Douglas, M. (1985). Risk Acceptability According to the Social Sciences, London: Routledge, Kegan \& Paul.

Dubet, F. (2006). El declive de la institución. Profesiones, sujetos e individuos en la modernidad. Barcelona: Gedisa.

Duschatzky, S., y Corea, C. (2002). Chicos en banda. Los caminos de la subjetividad en el declive de las instituciones. Buenos Aires: Paidós.

Fassin, D. (1999). La patetización del mundo. Ensayo de antropología política del sufrimiento. En M. Viveros y G. Garay (Eds.), Cuerpos, diferencias y desigualdades (pp. 31-41). Santafé de Bogotá: Utópica. 
Fassin, D. (2003). Gobernar por los cuerpos, políticas de reconocimiento hacia los pobres y los inmigrantes en Francia.Cuadernos de Antropología Social, 17, 49-78.

Feher, M. (2009). Self-Appreciation; or the Aspirations of Human Capital. Public Culture, 21(1), 21-41. doi: 10.1215/08992363-2008-019

Genard, J. L. (2009). Une réflexion sur l'anthropologie de la fragilité, de la vulnérabilité et de la souffrance. En T. Périlleux \& J. Cultiaux, Destins politiques de la souffrance. Intervention sociale, justice, travail (pp. 27-43).Toulouse: Éditions érès.

Giddens, A. (1990). The Consequences of Modernity. Cambridge: Polity.

Giner, S. (2014). Sociodicea. Revista Internacional de Sociología, 72 (2), 287-302. doi:10.3989/ris.2013.09.12

Gouldner, A. (1968). The Sociologist as Partisan: Sociology and the Welfare State. The American Sociologist, 3,103-116.

Hillyard, P., Pantazis, C., Tombs, S., \& Gordon, D. (2004). Beyond Criminology: Taking Harm Seriously. London: Pluto Press.

Honneth, A. (2010). Reconocimiento y menosprecio. Sobre la fundamentación normativa de una teoría social. Madrid: Katz.

Honneth, A. (2011). La sociedad del desprecio. Madrid: Trotta.

Kleinman, A., \& Van der Geest, S. (2009). «Care» in health care: Remaking the moral world of medicine. Medische Antropologie, 21(1), 159-168. Luhmann, N. (1993). Risk: A Sociological Theory. New York: Aldine de Gruyter.

Madrid, A. (2010). La política y la justicia del sufrimiento. Madrid: Trotta.

Morris, D.B. (2002). The culture of pain. Berkley: University of California Press.

Paugam, S. (2007). Las formas elementales de la pobreza. Madrid: Alianza. Renault, E. (2009). The political philosophy of social suffering. En B. Paul de Bruin \& C.F. Zurn (Eds.), New Waves in Political Philosophy (pp. 158-176). New York: Palgrave Macmillan.

Rivera Beiras, I. (2014). Delitos de los Estados, de los mercados y daño social. Debates en Criminología crítica y Sociología jurídico-penal. Barcelona: Anthropos. 
Rose, N., \& Miller, P. (1992). Political Power beyond the State: problematic of government. The British Journal of Sociology, 43(2), 173-205. doi: $10.2307 / 591464$

Rummel, R.J. (1994). Deathby Government.New Brunswick: N.J.: Transaction Publishers.

Salcedo Megales, D. (2010). Los fundamentos normativos de las profesiones y los deberes de los trabajadores sociales. Trabajo Social Global, 1(1), 10-38.

Schweizer, H. (2010). La espera. Melodías de la duración. Madrid: Ediciones Sequitur.

Sennett, R. (2001). El declive del Hombre Público. Barcelona, Península.

Simmel, G. (1998). Les pauvres. Paris: PUF.

Soulet, M.H. (2005a). Reconsidérer la vulnérabilité. Empan,4(60), 24-29. doi: 10.3917/empa.060.0024

Soulet, M.H. (2005b). Une solidarité de responsabilisation. En J. Ion (Dir.), Le travail social en débat[s] (pp.86-103). Paris: La Découverte.

Soulet, M.H. (2014). Par-delà les príncipes normatifs surplombants, des enjeux professionnels de justesse. Journée Nationale de Bienne, 19 marzo 2014. Université de Fribourg. Consultado desde http://csias.ch/fileadmin/user_upload/public/pdf/veranstaltungen/2014 BBT_Referat_Soulet_f.pdf

Sumner, L. (1999). Welfare, Happiness \& Ethics. Oxford: Oxford U.P.

Tilly, Ch. (1997). Roads from Past to Future. Maryland: Rowman and Littlefield.

Wacquant, L. (2000). Las cárceles de la miseria. Buenos Aires: Editorial Manantial.

Wacquant, L. (2007). Los Condenados de la ciudad. Gueto, periferias y Estado. Madrid: Siglo Veintiuno.

Wacquant, L. (2010). Castigar a los pobres: el gobierno neoliberal de la inseguridad social. Barcelona: Gedisa.

Wilkinson, I. (2005). Suffering: A Sociological Introduction. Cambridge: Polity Press.

Wilkinson, I (2013). The Problem of Suffering as a Driving Force of Rationalization and Social Change. British Journal of Sociology, 64(1), 123-141. doi:10.1111/1468-4446.12009 
Wilson, R. A. \& Brown, R. D. (2011). Humanitarianism and Suffering. The Mobilization of Empathy. Cambridge: Cambridge University Press.

Zamanillo Peral, T., y Martín Estalayo, M. (2011). La responsabilidad política del trabajo social. Trabajo Social Global, 2(3), 97-115.

Begoña Abad Miguélez es profesora del Departamento de Sociología II de la Universidad del País Vasco

Dirección de contacto: Departamento de Sociología II. Facultad de Ciencias Sociales y de la Comunicación. Universidad del País Vasco. Barrio Sarriena s/n -48940- Leioa (Bizkaia), España. Email: begona.abad@ehu.eus 